OPEN ACCESS

Edited by:

Roger M. Bourne,

University of Sydney, Australia

Reviewed by:

Xudong Shen,

Guizhou Medical University

(GMU), China

Guolin Ma,

China-Japan Friendship

Hospital, China

*Correspondence:

$\operatorname{Bin} X U$

njxb1982@126.com

Mulong Du

drdumulong@njmu.edu.cn

Ming Chen

mingchenseu@126.com

tThese authors have contributed equally to this work as co-first authors

Specialty section:

This article was submitted to Cancer Imaging and Image-directed

Interventions,

a section of the journal

Frontiers in Oncology

Received: 28 July 2019 Accepted: 16 September 2019

Published: 04 October 2019

Citation

Zhang N, Wang X, Wang C, Chen S, Wu J, Zhang G, Zhu W, Liu J, Xu B,

Du $M$ and Chen M (2019) Diagnostic Accuracy of Multi-Parametric

Magnetic Resonance Imaging for

Tumor Staging of Bladder Cancer: Meta-Analysis. Front. Oncol. 9:981.

doi: 10.3389/fonc.2019.00981

\section{Diagnostic Accuracy of Multi-Parametric Magnetic Resonance Imaging for Tumor Staging of Bladder Cancer: Meta-Analysis}

Nieke Zhang ${ }^{1 \dagger}$, Xiaoyan Wang ${ }^{2 \dagger}$, Chunying Wang ${ }^{2 \dagger}$, Shuqiu Chen ${ }^{1}$, Jianping $W u^{1}$, Guangyuan Zhang ${ }^{1}$, Weidong Zhu ${ }^{1}$, Jing Liu ${ }^{1}$, Bin Xu ${ }^{1 *}$, Mulong $\mathrm{Du}^{3,4 *}$ and Ming Chen ${ }^{1 *}$

${ }^{1}$ Department of Urology, Affiliated Zhongda Hospital of Southeast University, Nanjing, China, ${ }^{2}$ Department of Nursing, Affiliated Zhongda Hospital of Southeast University, Nanjing, China, ${ }^{3}$ Jiangsu Key Laboratory of Cancer Biomarkers, Prevention and Treatment, Department of Environmental Genomics, Collaborative Innovation Center for Cancer Personalized Medicine, Nanjing Medical University, Nanjing, China, ${ }^{4}$ Department of Biostatistics, Center for Global Health, School of Public Health, Nanjing Medical University, Nanjing, China

Purpose: Evaluate the diagnostic accuracy of multi-parametric magnetic resonance imaging (mp-MRI) for local staging of bladder cancer (BCa).

Materials and Methods: The databases of PubMed, Web of Science, Wanfang, and CNKI were searched for related literatures about BCa diagnosed by mp-MRI from January 1, 2000 to April 12, 2019. The strict inclusion and exclusion criteria were set up to extract records. The Quality Assessment of Diagnostic Accuracy Studies (QUADAS)-2 was used to evaluate quality of the candidate studies. The pooled sensitivity, specificity, positive likelihood ratio (+LR), negative likelihood ratio $(-L R)$, and diagnostic odds ratio (DOR) were calculated to assess the diagnostic authenticity of mp-MRI. The summarized receiver operating characteristic (SROC) curve corresponding with the area under the curve (AUC) were analyzed to comprehensively evacuate the diagnostic value of mp-MRI.

Results: A total of 140 studies were retrieved by computer-based searching. After quality control, 4 studies with 259 patients were enrolled for meta-analysis. The pooled results showed 0.84 of sensitivity [95\% confidence interval $(\mathrm{Cl})=0.79-0.89$ ], 0.91 of specificity $(95 \% \mathrm{Cl}=0.87-0.93), 8.24$ of $+\mathrm{LR}(95 \% \mathrm{Cl}=4.87-13.92), 0.18$ of $-\mathrm{LR}$ (95\% Cl $=0.10-0.31), 49.42$ of DOR (95\% Cl $=19.07-128.09)$, and 0.946 of AUC. The Spearman correlation analysis found no threshold effect $(p=0.684)$. A significant heterogeneity existed among 4 included studies with sensitivity $\left(l^{2}=65.7 \%\right)$, specificity $\left(I^{2}=60.0 \%\right)$ and diagnostic OR $\left(I^{2}=67.5 \%\right)$. The Begg's test $(p=0.497)$ and the egger's test $(p=0.337)$ found no publication bias.

Conclusion: mp-MRI acts a good diagnostic performance for bladder cancer. It is plausible that mpMRls can be used as an important method for bladder cancer staging.

Keywords: bladder cancer, multi-parametric magnetic resonance imaging, diagnosis, staging, meta-analysis 


\section{INTRODUCTION}

Bladder cancer is one of the most common cancers worldwide with nearly 550,000 new cases diagnosed in 2018 and around 200,000 patients die from this disease. Its incidence and prevalence have been increasing constantly in the past decade $(1,2)$. Treatment recommendations of the practice guidelines are based on the tumor and grade which is determined by the combination of clinical symptoms and imaging parameters (3).

Currently, the multi-parametric magnetic resonance imaging (mp-MRI) is widely used for bladder cancer diagnosis and staging. It consists of the conventional sequence [T2-weighted anatomic imaging (T2WI)] and functional MRI techniques [dynamic contrast-enhanced (DCE) imaging and diffusionweighted imaging (DWI)] (4). Multi-parametric magnetic resonance imaging has the high sensitivity and specificity in diagnosing and staging the bladder cancer. In addition, it can provide more information about the morphology of bladder and the blood supply, so it is helpful for preoperative diagnosis of bladder cancer (4). In the recent decade, several studies have assessed the diagnosis value of mp-MRI in staging bladder cancer, however the sensitivity and specificity of each study were not in accordance.

This study is aimed to comprehensively evaluate the diagnostic ability of mp-MRI in staging bladder cancer and convincingly provide evidences for supporting the treatment in the clinic.

\section{MATERIALS AND METHODS}

\section{Searching Strategies}

The computer search was performed among the databases of PubMed, Web of Science, Wanfang, and CNKI with the search terms including ("bladder cancer" OR "BCa" OR "bladder carcinoma" OR "urinary bladder neoplasms") AND ("mp-MRI" OR "multi-parametric magnetic resonance imaging" OR "multiparametric MRI” OR “MRI” OR “magnetic resonance imaging”) AND ("staging” OR "stage") AND (“diagnosis" OR "diagnose"-). The studies were published from January 1, 2000 to April 12, 2019. Titles and abstracts were screened for relevance, full texts reviewed and the inclusion and exclusion criteria were applied to select the records.

\section{Inclusion Criteria}

The inclusion criteria were set as follows: (a) Studies of mp-MRI for local staging of the bladder cancer in human (field strength $\geq 1.5 \mathrm{~T}$ ); (b) Data was available to calculate the $2 * 2$ contingency table; (c) Pathological results were used as the reference standard; (d) Staging the bladder cancer by mp-MRI included T2WI, DWI, and DCE-MRI; (e) Number of patients $\geq 10$.

\footnotetext{
Abbreviations: mp-MRI, multi-parametric magnetic resonance imaging; $\mathrm{BCa}$, bladder cancer; (QUADAS)-2, The Quality Assessment of Diagnostic Accuracy Studies; +LR, positive likelihood ratio; - LR, negative likelihood ratio; DOR, diagnostic odds ratio; SROC, summarized receiver operating characteristic curve; AUC, the area under the curve; CI, 95\% confidence interval; T2WI, T2-weighted anatomic imaging; DCE, dynamic contrast-enhanced; DWI, diffusion-weighted imaging; TP, true positive; FP, false positive; FN, false negative; TN, true negative.
}

\section{Exclusion Criteria}

The exclusion criteria were set as follows: (a) The study was a case report, editorial, review, systematic review, or commentary; (b) Patients were included in another study; (c) Stage of bladder cancer was judged by only one reader based on imaging results.

\section{Risk Bias Assessment of Included Studies}

The quality of the included literature was assessed according to the QUADAS-2 tool recommended by the Cochrane collaboration web (5).

\section{Data Extraction}

Reading the title and abstract was the first step toward excluding the obviously irrelevant records. The full texts were then screened according to the inclusion and exclusion criteria. Information extracted from the records included characteristics of records [first author, publication year, study period, country and language, number of reader, golden standard, research type, the true positive(TP), false positive(FP), false negative(FN), true negative $(\mathrm{TN})$ ], characteristics of patients [number of patients(male and female) and age], and characteristics of mpMRI (manufacturer and model of the scanner, magnet strength, repetition time, echo time, slice thickness, slice gap, and flip angle of the T2WI, DWI, DCE).

\section{Statistical Method}

We used the Meta-DiSc 1.4, Stata 14.0, and Review Manager (RevMan. Version 5.3) to analyze data. First, Spearman correlation analysis was used to test heterogeneity caused by threshold effect, if $P>0.05$, means there is no heterogeneity, the fixed effect model is adopted; if $P<0.05$, means heterogeneity exists, the random effects model is adopted. We merged the evaluation index by calculating pooled sensitivity (Sen), pooled specificity (Spe), pooled positive likelihood ratio ( $+\mathrm{LR})$, pooled negative likelihood ratio (-LR), and pooled diagnostic odds ratio (DOR); then also drew a summarized receiver operating characteristic (SROC) curve and calculated the area under the curve (AUC). If $P<0.05$, the difference is statistically significant. We adopted the Begg's test and egger's test to check for publication bias, where if $p>0.05$ this means no publication bias is found (6).

\section{RESULTS}

\section{Records Searching}

Figure 1 shows the process of document searching and screening. A total of 140 records were originally searched. Among that, 23 records were removed because of the duplicate records; after looking through the title and abstract, 102 records were excluded. As followed as the strict inclusion and exclusion criteria, eventually 4 records were enrolled in qualitative analysis (7-10).

\section{Characteristics of Included Studies}

The characteristics of candidate studies are shown in Table 1. All 4 investigations were retrospective study within single center. The patients were Chinese in Zhang Wei and Xia Weili's studies and non-Chinese in the other two studies. The number of 


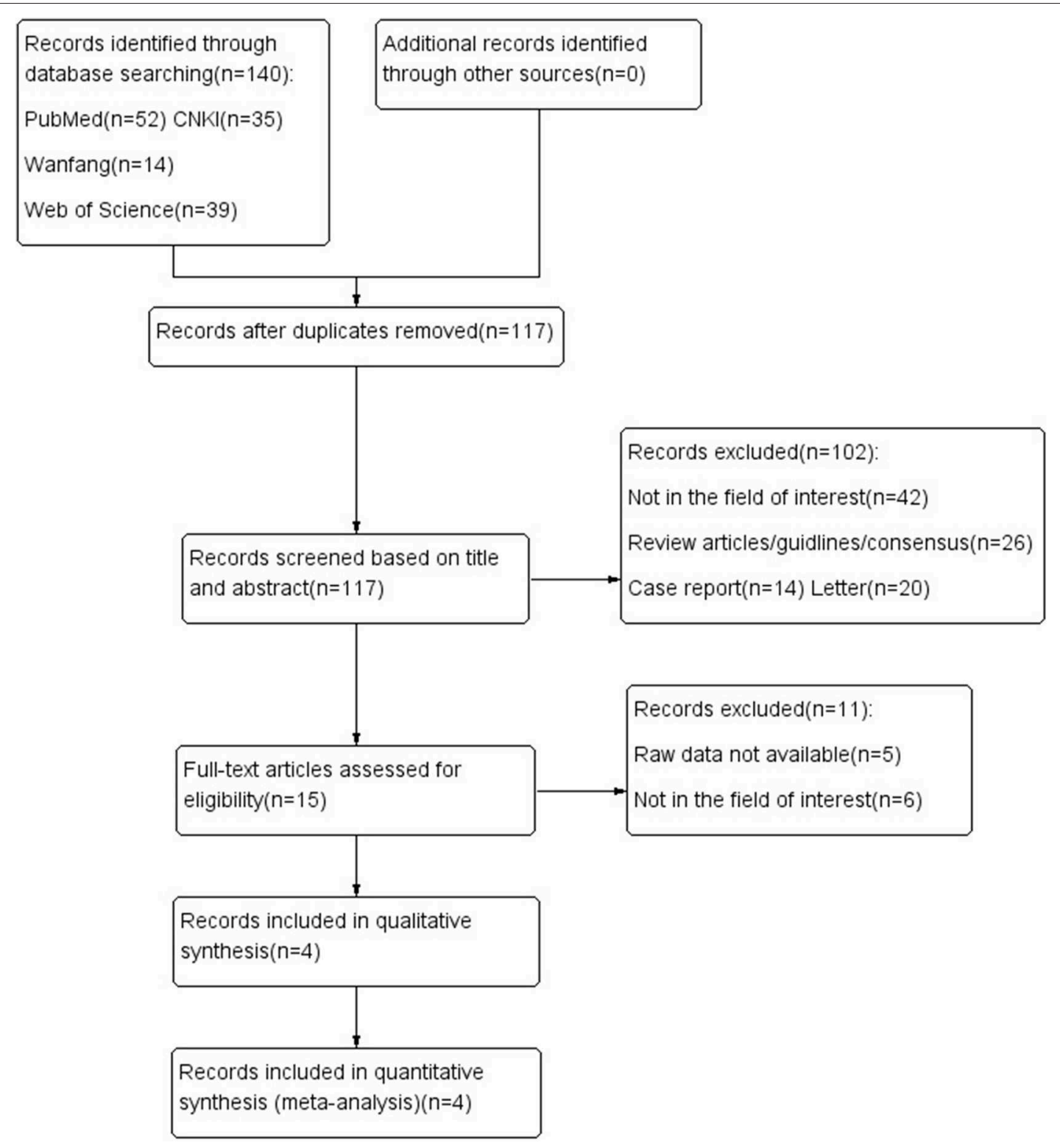

FIGURE 1 | Flow diagram showing study selection process for meta-analysis.

TABLE 1 | Characteristics of included studies.

\begin{tabular}{|c|c|c|c|c|c|c|c|c|c|c|c|c|c|}
\hline \multirow[t]{2}{*}{ References } & \multirow[t]{2}{*}{ Study period } & \multirow{2}{*}{$\begin{array}{l}\text { Country/ } \\
\text { Language }\end{array}$} & \multirow{2}{*}{$\begin{array}{c}\text { No. of } \\
\text { patients }\end{array}$} & \multicolumn{2}{|c|}{ Age(yrs) } & \multirow{2}{*}{$\begin{array}{l}\text { No. of } \\
\text { readers }\end{array}$} & \multirow{2}{*}{$\begin{array}{l}\text { Golden } \\
\text { standard }\end{array}$} & \multirow{2}{*}{$\begin{array}{l}\text { Research } \\
\text { type }\end{array}$} & \multirow[t]{2}{*}{ Male/female } & \multicolumn{4}{|c|}{ Raw data } \\
\hline & & & & Mean & Range & & & & & TP & FP & FN & TN \\
\hline Zhang et al. (9) & 2015.10-2017.03 & $\begin{array}{l}\text { China/ } \\
\text { Chinese }\end{array}$ & 55 & 58.67 & $48-68$ & 2 & $\begin{array}{l}\text { Pathologic } \\
\text { result }\end{array}$ & $\begin{array}{l}\text { Retrospective } \\
\text { study }\end{array}$ & $48 / 7$ & 48 & 8 & 7 & 157 \\
\hline $\begin{array}{l}\text { van der Pol et al. } \\
\text { (7) }\end{array}$ & $2011.08-2016.10$ & $\begin{array}{l}\text { USA } \\
\text { English }\end{array}$ & 45 & 69 & 44-89 & 2 & $\begin{array}{l}\text { Pathologic } \\
\text { result }\end{array}$ & $\begin{array}{l}\text { Retrospective } \\
\text { study }\end{array}$ & $33 / 12$ & 40 & 9 & 13 & 63 \\
\hline Barchetti et al. (8) & 2017.09-2018.07 & $\begin{array}{l}\text { Italy/ } \\
\text { English }\end{array}$ & 75 & 69 & $62-78$ & 2 & $\begin{array}{l}\text { Pathologic } \\
\text { result }\end{array}$ & $\begin{array}{l}\text { Retrospective } \\
\text { study }\end{array}$ & $62 / 13$ & 35 & 14 & 9 & 92 \\
\hline Xia et al. (10) & 2012.10-2016-12 & $\begin{array}{l}\text { China/ } \\
\text { Chinese }\end{array}$ & 84 & NR & NR & 2 & $\begin{array}{l}\text { Pathologic } \\
\text { result }\end{array}$ & $\begin{array}{l}\text { Retrospective } \\
\text { study }\end{array}$ & $46 / 38$ & 49 & 4 & 3 & 28 \\
\hline
\end{tabular}

TP, true positive; FP, false positive; FN, false negative; TN, true negative. 
the study patients ranged from 45 to 84 . The mean age of the included patients ranged from 58 to 69 years. Mp-MRI was interpreted when blinded to the reference standard in all of the studies, and the results of the imaging were read by two experienced readers independently. The interval between MRI and the reference standard was not provided in these studies. Seventy out of two hundred fifty-nine included patients were female.

The basic mp-MRI parameters of each study are summarized in Table 2. Zhang Wei's study used 1.5-T scanners, Christian B.'s study used both 1.5-T and 3.0-T, while the rest two studies used 3.0-T scanners. All studies used conventional sequence (T2WI) and functional imaging sequences (DWI, DCE).

\section{Quality Assessment}

The quality of the included studies was evaluated according to the QUADAS-2 (5), and the risk of bias and applicability concerns of 4 included studies is shown in Figure 2. In general, the quality of the included studies was considered high. Regarding the patient selection domain, Giovanni B.'s study was considered to have high risk of bias as the included patients were not identified by pathology. Regarding the index test domain, Giovanni B. and Zhang Wei's studies were considered to have unclear risk, because blinding was unclear. Regarding the reference standard domain, all 4 studies had unclear risk of bias as it is uncertain whether the interpretation of the reference standard used the blind method. Regarding the flow and timing domain, the included studies had low risk of bias. There was low concern for applicability with regard to the first three QUADAS-2 domains for all 4 included studies.

\section{Meta-Analysis}

The result of meta-analysis is showed in the Figures 3, 4. We found that the pooled sensitivity $=0.84(95 \%$ CI $0.79-0.89)$, pooled specificity $=0.91(95 \%$ CI $0.87-0.93)$, pooled $+\mathrm{LR}=$ 8.24 (95\% CI 4.87-13.92), pooled $-\mathrm{LR}=0.18$ (95\% CI 0.10-0.31), pooled DOR $=49.42(95 \%$ CI 19.07-128.09), and pooled AUC $=0.946$. All these findings suggest the mp-MRI has a strong diagnostic efficiency in bladder cancer.

\section{Heterogeneity Test and Publication Bias}

Besides, we performed Spearman correlation analysis between Sen log and (1-Spe) log, and found no threshold effect $(p=$ 0.684). However, the result of heterogeneity test showed that there was a significant heterogeneity among these 4 studies within sensitivity $\left(I^{2}=65.7 \%\right)$, specificity $\left(I^{2}=60.0 \%\right)$, and diagnostic OR $\left(I^{2}=67.5 \%\right)$. These results indicated the randomized effects model for the above combined analysis. Furthermore, we did not find publication bias using both Begg's test $(p=0.497)$ and egger's test $(p=0.337)$, as shown in Figure 5.

\section{DISCUSSION}

There is an increasing number of patients who suffer from bladder cancer worldwide (1). With the development of technology and modern medicine, mp-MRI is wildly used in diagnosing and staging bladder cancer around

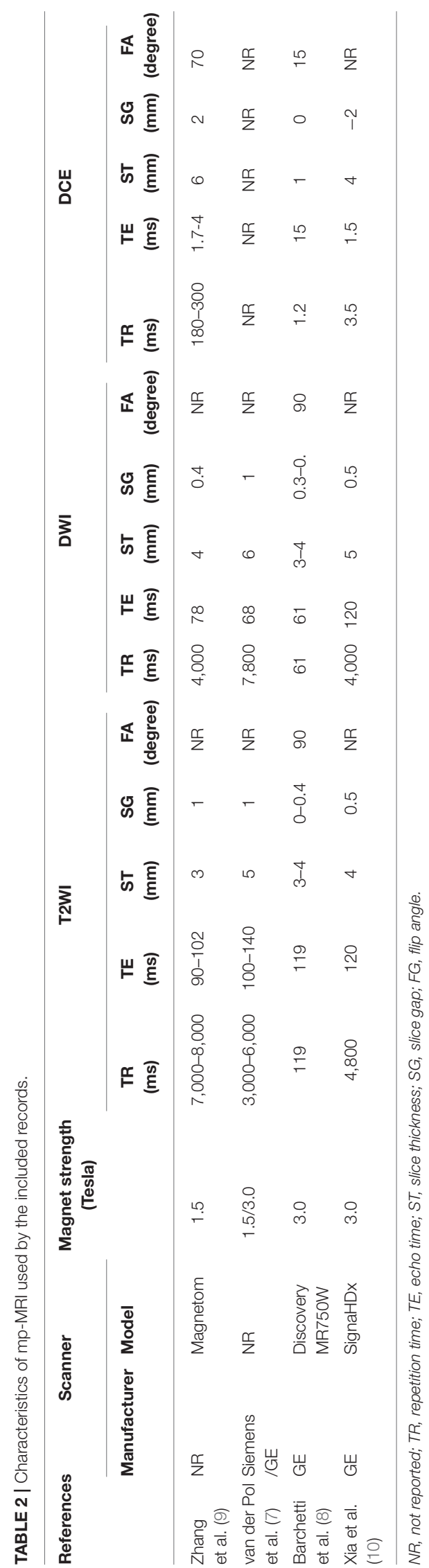




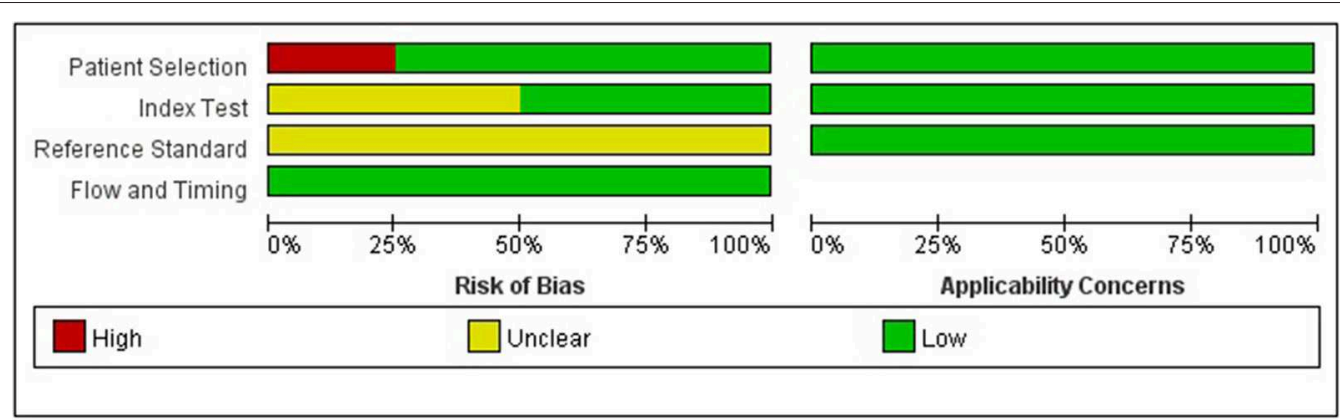

FIGURE 2 | Grouped bar charts show risk of bias and applicability concerns of 4 included records using QUADAS-2.
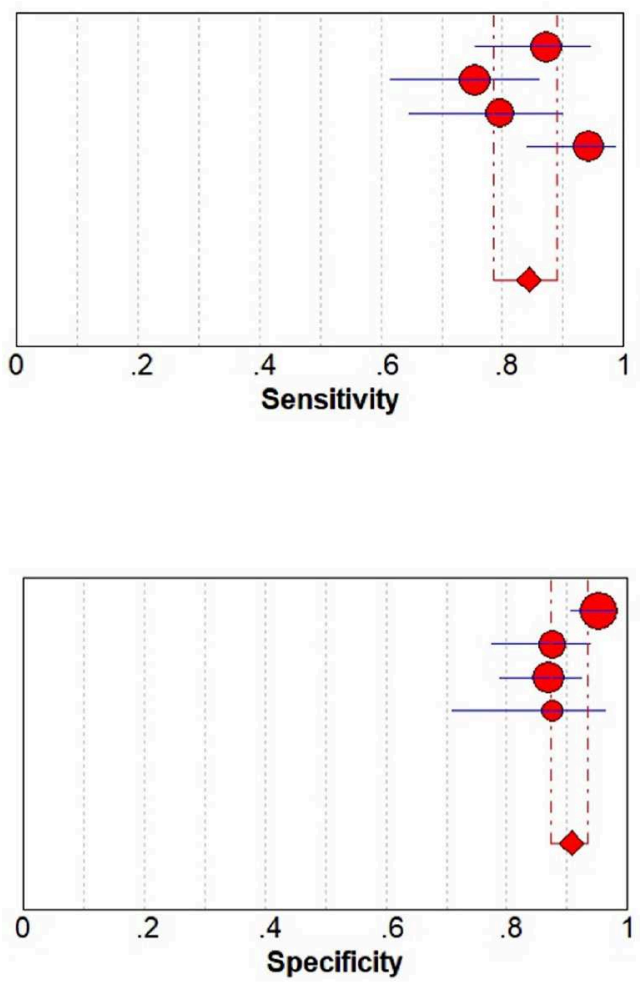

Zhang Wei 2018

Christian B. 2018

Giovanni B. 2019

Xia Weili 2018

Pooled Specificity $=0.91(0.87$ to 0.93$)$

Chi-square $=7.49 ; \mathrm{df}=3(p=0.0577)$

Inconsistency $($ I-square $)=60.0 \%$

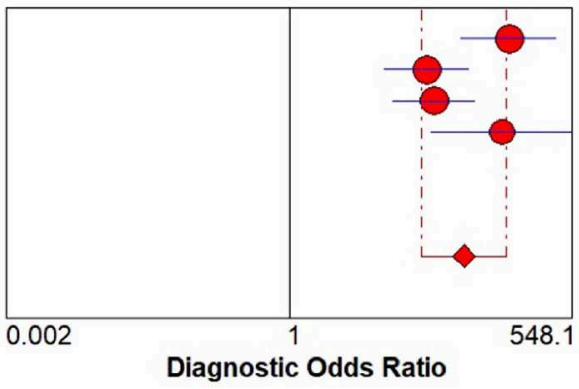

Zhang Wei 2018 Christian B. 2018

Giovanni B. 2019

Xia Weili 2018

Random Effects Model

Pooled Diagnostic Odds Ratio $=49.42$ (19.07 to 128.0 s

Cochran- $Q=9.22 ; \mathrm{df}=3(\mathrm{p}=0.0265)$

Inconsistency (I-square) $=67.5 \%$

Tau-squared $=0.6236$
Diagnostic OR (95\% Cl)

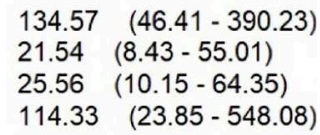

$25.56 \quad(10.15-64.35)$
$114.33 \quad(23.85-548.08)$

$\begin{array}{ll}0.95 & (0.91-0.98) \\ 0.88 & (0.78-0.94) \\ 0.87 & (0.79-0.93) \\ 0.88 & (0.71-0.96)\end{array}$

$0.87 \quad(0.76-0.95)$

$(0.62-0.86)$

$0.80 \quad(0.65-0.90)$

$0.94(0.84-0.99)$

$\begin{array}{lr}\text { Christian B. } 2018 & 0.75 \\ \text { Giovanni B. } 2019 & 0.80 \\ \text { Xia Weili 2018 } & 0.94 \\ & \\ & \\ & \\ \text { Pooled Sensitivity }=0.84(0.79 \text { to } 0.89) \\ \text { Chi-square }=8.74 ; \text { df }=3(p=0.0329) \\ \text { Inconsistency (I-square })=65.7 \%\end{array}$

Christian B. 2018
Giovanni B. 2019
Xia Weili 2018


Pooled Sensitivity $=0.84(0.79$ to 0.89
Chi-square $=8.74 ;$ df $=3(p=0.0329)$
Inconsistency $($ l-square $)=65.7 \%$ 
the world (4), but its effectiveness fluctuates a lot. In this study, we integrated all current studies about mpMRI clinical application to evaluate the diagnostic performance of mp-MRI for bladder cancer staging. The pooled sensitivity, specificity, and AUC are 0.84, 0.91, and 0.946, respectively, and these high values indicate high efficiency of mp-MRI diagnosing and staging the bladder cancer, and provide scientific evidence for clinical diagnose and decision-making.

The golden standard of diagnosis for staging of bladder cancer is the biopsy through cystoscopy, and some imaging methods such as X-ray and CT are also wildly adopted for reference. However, there are some limits of these traditional methods of diagnosis, for example, they cannot guarantee the safety and accuracy at the same time. In recent years, the MRI protocol has been wildly used in diagnosing and staging bladder cancer, and current studies demonstrate that it may largely effect the diagnostic accuracy for local staging of bladder cancer $(11,12)$. Especially the multi-parametric approach consists of the conventional sequence [T2-weighted anatomic imaging (T2WI)] and functional MRI techniques [dynamic contrastenhanced (DCE) imaging and diffusion-weighted imaging (DWI)]. Compared with only using conventional sequences or only a single functional technique, the mp-MRI has a higher accuracy in diagnosing and staging bladder cancer (13). T2WI has high spatial resolution so it can differentiate the layers of the bladder. On the other hand, the functional techniques also have advantages as they can better depict the tumor itself (DWI). Furthermore, some other imaging features, such as the tumor stalk and submucosa linear enhancement, make it possible for DWI to local stage the bladder cancer (14). Therefore, combining the anatomical sequence (T2WI) with the functional sequences (DWI, DCE), the performance of MRI for diagnosing and staging bladder cancer will be improved. In addition, 3.0-T MRI benefits the tumor detection because it can increase the Signal to Noise Ratio of the image and improve the spatial and temporal resolution of the image. Multiple studies have proved that 3.0T MRI shows a better specificity and sensitivity than 1.5-T MRI when used to diagnose and stage bladder cancer. Therefore, the guidelines recommend the use of multi-parametric 3-T MRI in the clinical diagnosis to improve the diagnostic accuracy for determining bladder cancer T stage (15). The T stage of the tumor is classified into four categories [T1 or lower, T2 (T2a or T2b), T3 (T3a or T3b), and T4 (T4a or T4b)] in accordance with the 8th TNM classification of malignant tumors which was published in 2017 (16).

On T2W images, a T2 hypo-intense band appeared by the normal detrusor muscle outlining the bladder lumen (17). Stage Ta, Tis, or T1 bladder cancer shows an intact T2 hypointense band. The T2 hypo-intense band and the irregular inner margin at the junction of bladder tumor and normal tissue suggest $\mathrm{T} 2 \mathrm{a}$ stage. In addition, in the T2b stage, the T2 hypo-intense band is disrupted, without invasion of the adjacent peri-vesical fat $(17,18)$. When the tumor signal extends into the fat, it is considered as T3 stage, when it extends into the adjacent organs or the pelvic wall, T4 stage is considered.
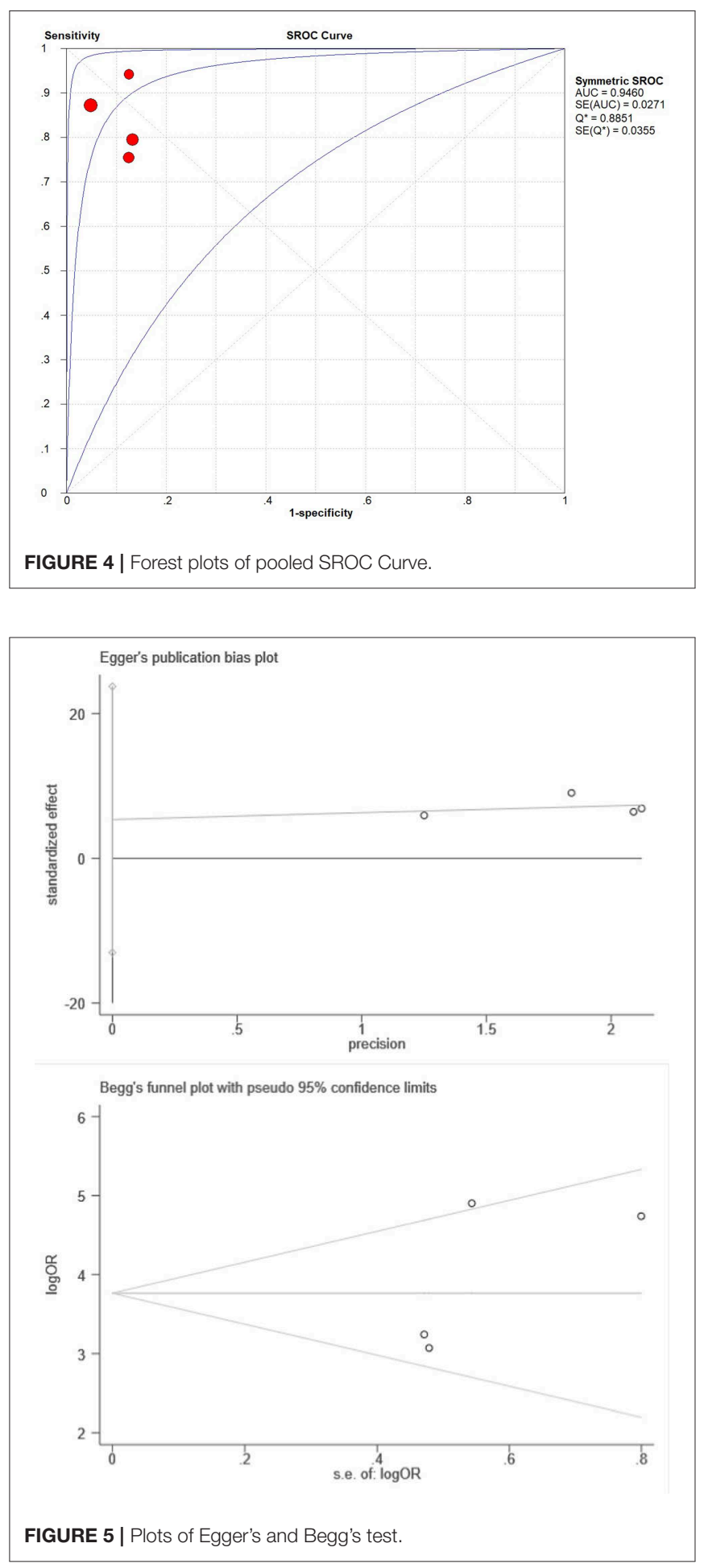

On DW and DCE images, the bladder mucosa and lamina propria are enhanced, while the underlying detrusor muscle remains with high signal intensity in the early phase contrastenhanced images about bladder cancer $(17,18)$. The early postcontrast images about Ta, Tis, and T1 stage show that the muscle underlying the tumor remains with high signal intensity. In 
addition, beneath the tumor, the enhancement of the intact submucosa linear that presents in the early phase images also indicates the stage of Ta, Tis, or T1 $(11,18,19)$. On the early postcontrast images, if the inner margin at the junction of the bladder tumor and muscle is irregular, the disease is in the stage of T2a. However, in the images of stage T2b disease, the hypo-intense muscle wall is disrupted and the peri-vesical fat is not extended by the early enhancing tissue. In the images of T3 and T4 tumors, the early abnormal enhancing tissue extends into the peri-vesical fat and surrounding tissues or organs $(11,12,19)$.

There are some limitations in this study. First, two of the included studies, respectively calculated the data achieved by two readers, so we had to choose one reader's results randomly. Another limitation is the small sample size, for only 4 records were included, which can influence the accuracy of the research result and make it difficult for subgroup analysis.

\section{CONCLUSION}

This study supported that mp-MRI acted a high diagnostic accuracy for staging of bladder cancer, and proved that $\mathrm{mp}$ MRI can be used as one of the main diagnostic methods of bladder cancer in the clinic. These findings will provide an

\section{REFERENCES}

1. Bray F, Ferlay J, Soerjomataram I, Siegel RL, Torre LA, Jemal A. Global cancer statistics 2018: GLOBOCAN estimates of incidence and mortality worldwide for 36 cancers in 185 Countries. CA Cancer J Clin. (2018) 68:394-424. doi: 10.3322/caac. 21492

2. Chavan S, Bray F, Lortet-Tieulent J, Goodman M, Jemal A. International variations in bladder cancer incidence and mortality. Eur Urol. (2014) 66:59-73. doi: 10.1016/j.eururo.2013. 10.001

3. Degeorge KC, Holt HR, Hodges SC. Bladder cancer: diagnosis and treatment. Am Fam Phys. (2017) 96:507-14.

4. de Haas RJ, Steyvers MJ, Futterer JJ. Multiparametric MRI of the bladder: ready for clinical routine? Am J Roentgenol. (2014) 202:1187-95. doi: 10.2214/AJR.13. 12294

5. Whiting PF, Rutjes AW, Westwood ME, Mallett S, Deeks JJ, Reitsma JB, et al. QUADAS-2: a revised tool for the quality assessment of diagnostic accuracy studies. Ann Intern Med. (2011) 155:529-36. doi: 10.7326/0003-4819-155-8-20111018000009

6. Deeks JJ, Macaskill P, Irwig L. The performance of tests of publication bias and other sample size effects in systematic reviews of diagnostic test accuracy was assessed. J Clin Epidemiol. (2005) 58:882-93. doi: 10.1016/j.jclinepi.2005. 01.016

7. van der Pol CB, Shinagare AB, Tirumani SH, Preston MA, Vangel MG, Silverman SG. Bladder cancer local staging: multiparametric MRI performance following transurethral resection. Abdom Radiol. (2018) 43:2412-23. doi: 10.1007/s00261-0171449-0

8. Barchetti G, Simone G, Ceravolo I, Salvo V, Campa R, Del Giudice F, et al. Multiparametric MRI of the bladder: inter-observer agreement and accuracy with the Vesical Imaging-Reporting and Data System (VI-RADS) at a single reference center. Eur Radiol. (2019). 29:5498-506. doi: 10.1007/s00330-019-0 $6117-8$ important theoretical basis for clinical physicians to judge and make clinical decisions on bladder cancer. Also, it is necessary to conduct high-quality, multi-center studies to increase sample size to further explore the diagnostic value of mp-MRI in staging the bladder cancer.

\section{AUTHOR CONTRIBUTIONS}

BX put forward the idea. NZ and XW searched the literature. NZ and CW extracted and analyzed the data. SC, JW, GZ, WZ, and JL provided statistical advice. NZ wrote the manuscript. MD and $\mathrm{MC}$ reviewed and revised the manuscript.

\section{FUNDING}

This study was funded by the National Natural Science Foundation of China (No. 81872089, 81370849, 81672551, 81300472, 81070592, 81202268, and 81202034), Natural Science Foundation of Jiangsu Province (BK20161434, BL2013032, BK20150642, and BK2012336), Six talent peaks project in Jiangsu Province, Jiangsu Provincial Medical Innovation Team (CXTDA2017025), and Jiangsu Provincial Medical Talent (ZDRCA2016080).

9. Zhang $\mathrm{W}$, Wang $\mathrm{ZB}$, Zhang $\mathrm{L}$, Li YC. Clinical value of $\mathrm{mp}$ MRI in comprehensive diagnosis of bladder cancer. $J$ Pract Med. (2018) 34:1010-15. doi: 10.3969/j.issn.1006-5725.2018. 06.034

10. Xia WL, Wang LF, Zhang XX, Xu CM, Qu JR, Li HL, et al. The preoperative diagnosis value of $3.0 \mathrm{~T}$ MRI for muscle invasive bladder cancer. J Clin Radiol. (2018) 37:1860-64. doi: 10.13437/j.cnki.jcr.2018. 11.023

11. Wang HJ, Pui MH, Guan J, Li SR, Lin JH, Pan B, et al. Comparison of early submucosal enhancement and tumor stalk in staging bladder urothelial carcinoma. Am J Roentgenol. (2016) 207:797-803. doi: 10.2214/AJR.16. 16283

12. Takeuchi M, Sasaki S, Ito M, Okada S, Takahashi S, Kawai T, et al. Urinary bladder cancer: diffusion-weighted MR imagingaccuracy for diagnosing $\mathrm{T}$ stage and estimating histologic grade. Radiology. (2009) 251:112-21. doi: 10.1148/radiol.25110 80873

13. Panebianco V, De Berardinis E, Barchetti G, Simone G, Leonardo C, Grompone MD, et al. An evaluation of morphological and functional multiparametric MRI sequences in classifying non-muscle and muscle invasive bladder cancer. Eur Radiol. (2017) 27:3759-66. doi: 10.1007/s00330-0174758-3

14. Kobayashi S, Koga F, Yoshida S, Masuda H, Ishii C, Tanaka $\mathrm{H}$, et al. Diagnostic performance of diffusion-weighted magnetic resonance imaging in bladder cancer: potential utility of apparent diffusion coefficient values as a biomarker to predict clinical aggressiveness. Eur Radiol. (2011) 21:2178-86. doi: 10.1007/s00330-0112174-7

15. van der Pol CB, Chung A, Lim C, Gandhi N, Tu W, McInnes $\mathrm{MDF}$, et al. Update on multiparametric MRI of urinary bladder cancer. J Magn Reson Imaging. (2018) 48:882-96. doi: 10.1002/jmri. 26294

16. Brierley J, Gospodarowicz MK, Wittekind C. TNM Classification of Malignant Tumours. 8th ed. Chichester: Chichester Wiley (2017).

17. Vikram R, Ng CS, Tamboli P, Tannir NM, Jonasch E, Matin SF, et al. Papillary renal cell carcinoma: radiologic-pathologic correlation and 
spectrum of Disease. Radiographics. (2009) 29:741-54. doi: 10.1148/rg.2930 85190

18. Takeuchi M, Sasaki S, Naiki T, Kawai N, Kohri K, Hara M, et al. MR imaging of urinary bladder cancer for T-staging: a review and a pictorial essay of diffusion-weighted imaging. $J$ Magn Reson Imaging. (2013) 38:1299-309. doi: 10.1002/jmri. 24227

19. Matsuki M, Inada Y, Tatsugami F, Tanikake M, Narabayashi I, Katsuoka Y. Diffusion-weighted MR imaging for urinary bladder carcinoma: initial results. Eur Radiol. (2007) 17:201-4. doi: 10.1007/s00330-0060281-7
Conflict of Interest: The authors declare that the research was conducted in the absence of any commercial or financial relationships that could be construed as a potential conflict of interest.

Copyright (c) 2019 Zhang, Wang, Wang, Chen, Wu, Zhang, Zhu, Liu, Xu, Du and Chen. This is an open-access article distributed under the terms of the Creative Commons Attribution License (CC BY). The use, distribution or reproduction in other forums is permitted, provided the original author(s) and the copyright owner(s) are credited and that the original publication in this journal is cited, in accordance with accepted academic practice. No use, distribution or reproduction is permitted which does not comply with these terms. 